\title{
A formação dos conhecimentos em recursos hídricos e aplicações em tomadas de decisões
}

JOSÉ NILSON B. CAMPOS ${ }^{\text {e }}$ VANESSA RIBEIRO CAMPOS ${ }^{I I}$

\section{Introdução}

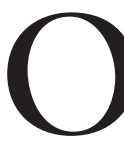

ESTUDO da geração dos conhecimentos em gestão de águas e suas aplicações pela sociedade constitui-se o principal objetivo deste artigo. A pesquisa cobre o período mais recente iniciando na segunda metade do século XX até os dias atuais. Nesse intervalo deram-se mudanças significativas de paradigmas.

Para Wheaton (1985), há duas maneiras de descrever a História. Na primeira, apresenta-se uma sucessão de eventos políticos distribuída no tempo por meio de uma matriz de datas de eleições, de batalhas, de golpes de Estado, de promulgação de leis etc. A segunda maneira, mais aplicada nos tempos atuais, estuda-se a evolução de ideias, de conceitos, das instituições sociais que afetaram e foram afetadas por essas ideias.

A segunda abordagem foi adotada neste artigo. E trata das interações entre as ciências e a sociedade na gestão de águas. As ciências criam conhecimentos que dão origem a ideias; as ideias dominantes transformam-se em paradigmas; a sociedade transforma os paradigmas em práticas; os políticos traduzem as práticas sociais em leis e regulamentos. Esse processo pode identificar, no campo teórico, a evolução do modelo de gestão de águas no Brasil.

O planejamento e a gestão de recursos hídricos têm estreita proximidade com as demandas sociais e as ações políticas. Até a década de 1970, muitas ações eram implementadas sem o apoio de uma base sólida do conhecimento científico. Como não eram submetidas a avaliações críticas, por serem aceitas como dogmas, as propostas de governos eram consideradas como as melhores soluções. Foi nesse contexto que se estabeleceu o aumento da oferta de água para resolver todos os problemas de escassez. Assim, a formação de novos conhecimentos científicos em gestão de águas ficava inibida.

As mudanças de atitude iniciaram com a constatação pela sociedade de que o modelo centrado na oferta para atender os avanços dos usos das águas era insustentável. Em 1983, A Assembleia Geral da ONU criou o CMMAD Conselho Mundial de Desenvolvimento e Meio Ambiente (World Comission on Environment and Development - WCED) com a incumbência de examinar 
as questões críticas de meio ambiente e desenvolvimento. Em 1987, o CMMAD publicou o notável relatório Nosso Futuro Comum (Our Commum Future) o qual representou um marco na visão mundial do meio ambiente (WCED, 1987). O relatório enfatizou a necessidade de aumentar a capacidade de previsão dos impactos ambientais para a implementação do desenvolvimento sustentável. A gestão racional dos recursos hídricos recebeu destaque especial entre os idealizadores do novo modelo.

Em 1992, aconteceu a Conferência das Nações Unidas sobre o Meio Ambiente e o Desenvolvimento (Rio 92) da qual resultou a Agenda 21. O Capítulo 18 da Agenda foi dedicado à proteção da qualidade e do abastecimento dos recursos hídricos. Assim, em razão dessa nova política mundial, houve uma crescente demanda por conhecimentos em gestão ambiental e de águas (United Nations, 2012).

A abordagem da água como bem econômico ganhou destaque nas discussões da política de águas do Brasil. Após a promulgação da Lei n.9.433/1997, a cobrança da água bruta passou a ser adotada como instrumento de gestão de águas. Muitas pesquisas, teses e debates foram centrados nesse tema: Motta (1998); Ribeiro, Lanna e Pereira (1999); Granziera (2000); Campos e Studart (2000). Em eventos da Associação Brasileira de Recursos Hídricos (ABRH), a cobrança era considerada como uma grande solução para aumentar a eficiência do uso das águas.

Mais recentemente, iniciou-se uma abordagem mais crítica sobre o tema. A limitação dos instrumentos econômicos associados ao princípio da precaução foi abordada por Gonçalves (2013). O autor considera que os modelos formais que interpretam o princípio da precaução em termos econômicos colaboram no entendimento do conceito de precaução e na tomada de decisão. Hoje, a comunidade de recursos hídricos, em seus debates na lista de discussão da ABRH, já percebe também as limitações da cobrança. Novos conhecimentos são demandados para avaliar a eficiência do atual modelo de administrar os usos das águas.

A Conferência Rio+20 foi aguardada com muita expectativa e esperança por defensores da política mundial da sustentabilidade. O encontro ocorreu no Rio de Janeiro em junho de 2012. Entre os principais temas do encontro estava a Economia Verde, definida pelo Programa das Nações Unidas para o Meio Ambiente (Pnuma), ou United Nations Environment Programme (Unep, 2011), como: "aquela que resulta na melhoria do bem-estar humano ao mesmo tempo em que reduz significativamente os riscos ambientais e a escassez ecológica".

O principal documento do encontro foi o texto "The future we want" (United Nations, 2012). O documento reafirma os princípios da Declaração em Ambiente e Desenvolvimento emanados do Encontro do Rio em 1992. A questão das mudanças climáticas também foi muito debatida. Em linhas gerais, em termos de princípios, não há mudanças substanciais em relação ao documento da Rio 92. 
Neste artigo analisa-se, em uma perspectiva teórica e prática, a formação do conhecimento científico relacionada aos temas água e suas aplicações em gestão de recursos hídricos. Também, buscam-se analisar as mudanças de visões sobre os modelos de gestão de águas.

O artigo está organizado em cinco seções. A seção 2 apresenta os conceitos relacionados à formação dos conhecimentos em matemática, em ciências empíricas e em ciências sociais. A seção 3 descreve a abordagem utilizada na década de 1970 para lidar com problemas de escassez de águas. A seção 4 trata da abordagem sobre o mesmo problema na década de 1990. A seção 5 versa sobre os processos sociais de aplicação dos conhecimentos na tomada de decisões em gestão de águas. A seção 6 apresenta as reflexões finais e os desafios a serem enfrentados no futuro próximo em termos de produção de conhecimentos em recursos hídricos.

\section{Sobre a formação dos conhecimentos}

A formação do conhecimento se dá de maneira distinta segundo o tipo de ciência. O artigo apresenta estudo sucinto sobre as formações dos conhecimentos segundo três categorias de ciências: a matemática, as ciências empíricas e as ciências sociais. Os conhecimentos em gestão de recursos hídricos estão relacionados a essas três classes de ciências. Os conhecimentos matemáticos são usados para dar sustentação aos modelos que descrevem a natureza; os conhecimentos em ciências empíricas, como a hidrologia, a geologia, e outras, são aplicados para entender o aparecimento e movimentação das águas na Terra; por sua vez, as ciências sociais são aplicadas para a administração das distribuição e controle do uso das águas pelos diversos segmentos da sociedade.

\section{A formação do conbecimento em matemática}

A teoria matemática é formada por deduções lógicas a partir de outras proposições previamente estabelecidas. Esse procedimento desce até uma origem arbitrária, formada de axiomas e postulados, na qual as proposições são aceitas sem provas. Os matemáticos são extremamente rígidos no processo de formação e acumulação do conhecimento.

Os conhecimentos matemáticos evoluem a partir da sequência teórica formada. A partir de cada teorema, devidamente provado, formam-se ramos de outros teoremas por ele suportados. Se, por acaso, um teorema formador de um ramo vier a ser falso, todo aquele ramo por ele suportado desmoronará. Todos os esforços despendidos terão sido em vão.

Ao longo desse processo, acumularam-se muitas ferramentas matemáticas que hoje são usadas e aplicadas em ciências empíricas e em ciências sociais. Com a aplicação correta de conhecimentos matemáticos em ciências empíricas, propicia-se a certeza de que as respostas numéricas estão corretas. As dúvidas e incertezas permanecem nas limitações do método indutivo.

\section{A formação do conbecimento nas ciências empiricas}

No século XIX, a civilização ocidental tinha tanta confiança na matemática 
que havia a crença de que o universo poderia ser descrito por um conjunto infinito de equações diferenciais auto solucionáveis. Segundo Magee (2000), René Descartes (1596-1650) encantava-se com as certezas matemáticas e sonhava em matematizar as ciências empíricas. A questão central de Descartes era: haveria nos conhecimentos não matemáticos premissas tais que pudessem conduzir à certeza?

O termo cartesiano, decorrente do sonho de Descartes, entrou no dicionário. Pelo lado positivo, significa que os rigores matemáticos são considerados na análise; pelo lado mais crítico, significa apego aos conceitos matemáticos e afastamento dos reais problemas da sociedade.

Com o avanço do espírito crítico dos cientistas, já se aceita que nenhuma ciência empírica, não importa quão bem tenha suas leis empacotadas em matemática sofisticada, pode atingir a certeza da matemática (Ince, 1987 p.35).

Nas ciências empíricas, as teorias são formadas mediante a observação da natureza e do estabelecimento de leis para representá-las. Na formação do conhecimento usa-se o raciocínio indutivo, que vai do particular para o geral. Como tal, esse conhecimento é limitado e sujeito a erros nas inferências.

A terceira lei de Newton, da ação e reação, segundo a qual a toda ação corresponde uma reação igual, em mesma direção, e em sentido contrário, foi provada, pela teoria da relatividade de Einstein, não ser válida em determinadas condições. Todavia, nesse caso, a limitação da validade universal da teoria não impediu que o conhecimento gerado tenha sido, e continue sendo, de grande utilidade na tecnologia. Nesse sentido é que os epistemólogos afirmam que toda teoria é provisória e está à espera de uma teoria melhor que venha a substituí-la.

Nas ciências hidrológicas, embora muito conhecimento tenha sido formado ao longo dos séculos, o reconhecimento como um ramo da geofísica se dá em 1922 quando foi formada a Associação Internacional de Ciências Hidrológicas. Porém foi somente a partir do segundo meado do século XX que a Hidrologia ganhou força como ciência e objeto de pesquisas nas grandes universidades do mundo.

Com o advento dos computadores eletrônicos e dos modelos matemáticos, o ritmo de criação do conhecimento, no âmbito das ciências hidrológicas, foi acelerado. Todavia, nessa linha, infelizmente, há muitas generalizações falsas, como resultado de uma mistura entre matemática e ciências empíricas. Confunde-se, às vezes, o modelo que simplifica o mundo real com o mundo real. Um cuidado especial com a formação do conhecimento em ciências hidrológicas deve ser tomado quanto a esse aspecto.

\section{A formação do conbecimento nas ciências sociais}

Nas ciências sociais o processo de construção do conhecimento é bem distinto daquele relativo às ciências empíricas e às matemáticas. As pessoas, em particular, e as sociedades, em seu conjunto, não se comportam como a natureza. Se, na natureza, respostas a impulsos semelhantes são iguais, na sociedade, o 
comportamento é bem diverso. Além do mais, as transformações sociais são bem mais dinâmicas do que as transformações na natureza.

Nas ciências sociais criam-se modelos teóricos de organização da sociedade e, quando aceitos, esses modelos são implementados. Mediante a observação, o monitoramento, das respostas da sociedade aos modelos implementados parte-se para o aperfeiçoamento desses modelos ou mesmo criação e implementação de novos modelos. Esse é um processo característico de formação e acumulação de conhecimento em ciências sociais.

Nesse contexto, a formação do conhecimento se dá por meio do raciocínio dedutivo: do geral para o particular. Não se pode, contudo, perder da mente que os modelos gerais são teóricos ou abstratos.

Esse processo de formação do conhecimento é bem perceptível no campo da gestão de recursos hídricos, principalmente no momento atual. Hoje, a sociedade está partindo para a criação de outros modelos com apoio em novos paradigmas. Certamente, ao longo do tempo, os novos modelos devem ser aprimorados. Porém, em não se analisando o processo de uma forma crítica, corre-se o risco de transformar os atuais conhecimentos em dogmas e retardar o avanço das ciências.

\section{A busca do conhecimento para enfrentar a escassez de águas}

No Brasil a busca do conhecimento para construir políticas públicas para resolver problemas de escassez de águas se dá na busca do conhecimento do Nordeste brasileiro, conhecido por recorrentes e catastróficas secas (Campos, 2014). Na sessão de 30 de maio de 1859, presidida por Dom Pedro II, nasceu uma comissão de engenheiros e naturalistas brasileiros para explorar algumas das províncias menos conhecidas do Brasil. A comissão deveria também fazer uma coleção de produtos orgânicos e inorgânicos para o Museu Nacional e ainda conhecer os costumes indígenas.

\section{Abordagens na década de 1970}

Em 1974 a Academia Nacional de Ciências dos Estados Unidos criou um painel ad hoc para emitir relatório sobre tecnologias promissoras e oportunidades de pesquisas que pudessem ser aplicadas em busca de mais águas para as terras áridas. Especialistas de várias partes do mundo se reuniram e abordaram técnicas para lidar com o problema da escassez de água. As principais técnicas discutidas durante o encontro foram: colheita de águas de chuvas; agricultura de run-off; reúso de água; redução de evaporação das superfícies de água; redução de perdas por infiltração; irrigação por gotejamento; dessalinização; seleção e manejo de culturas para uso mais eficientes da água (National Academy of Sciences, 1974).

A colheita de águas de chuvas constitui-se em uma técnica milenar já empregada por populações maias e astecas. Muitos estudos foram desenvolvidos para aprimorar e avaliar a economicidade da técnica. 
O reúso de águas vem ganhando mais importância e aceitação pela sociedade com o passar do tempo e com o agravamento dos problemas de escassez. O reúso de efluentes de tratamento é aplicado para alguns tipos de uso, excetuando-se, ainda, os usos para abastecimento doméstico. A prática do reúso, todavia, não é nova. O reúso em irrigação das águas de retorno (cerca de $30 \%$ ) tem acontecido normalmente ao longo dos séculos e é considerado nos balanços hídricos de bacias hidrográficas. Viessman e Welty (1985) afirmam que em 1965, nos Estados Unidos, cada galão de água usado na indústria reciclava em média 25 vezes antes de ser jogada fora. A tendência ao reúso deve aumentar à medida que o custo da água se torna mais alto. Os problemas maiores estão nos aspectos culturais e econômicos.

A redução da evaporação de água das superfícies dos lagos naturais e artificiais foi objeto de pesquisa na esperança de conseguir mais eficiência dos reservatórios em regiões áridas sujeitas a altas taxas de evaporação. Foram pesquisadas várias técnicas como filme de polietileno, cobertura dos lagos com mantas etc.; todavia, nenhuma das técnicas pesquisadas conseguiu sucesso suficiente para entusiasmar a sociedade e evoluir para aplicações em larga escala em grandes lagos.

A redução das perdas por infiltração, em sua essência, deve resultar de ações de gerenciamento. Em grandes áreas de irrigação, a redução se dá por substituição de canais de terra por canais impermeáveis. Nos sistemas de distribuição das cidades, a redução das perdas se dá mediante monitoramento acompanhado por ações de manutenção. O aprimoramento de técnicas de monitoramento e de administração desses sistemas foi a estratégia utilizada em países desenvolvidos para reduzir essas perdas a valores aceitáveis. A técnica de auditoria de água, mediante medições e modelos matemáticos, fornece elementos preciosos para a redução de perdas (National Academy of Sciences, 1974).

No Brasil, as perdas nos sistemas de abastecimento de água das cidades ainda são demasiadamente elevadas, chegando, em média, próximas a $40 \%$ (Abes, 2013). Embora já haja muitos conhecimentos científicos sobre o assunto, muitas ações tomadas são desprovidas de uma base científica mais aprofundada. Nessa situação, o problema sai da esfera do conhecimento científico, para entrar na prática gerencial e nas decisões políticas.

A irrigação por gotejamento, em essência, se constitui em uma prática que vem crescendo à medida que aumentam os problemas de escassez de água. Trata-se hoje de uma tecnologia dominada por técnicos e cientistas. A questão que se colocava na década de 1970 era a definição do instante, a partir do qual seria viável substituir outros sistemas de irrigação em funcionamento, com alguma vida útil restante, por um sistema de gotejamento. Deve-se ressaltar, todavia, que no Nordeste semiárido muitos perímetros de irrigação construídos na década de 1980, com a técnica de inundação, de baixa eficiência, ainda continuam ativados. 


\section{A escassez de água no contexto da gestão: abordagem dos anos 1990}

A partir da década de 1980, os estudos para a gestão da escassez de águas foram inseridos no âmbito da gestão dos recursos hídricos. Em 1992, o Bureau de Tecnologia e Ciências das Águas, na comemoração do seu décimo aniversário, promoveu um evento, já sob o paradigma do desenvolvimento sustentável, Sustaining Our Water Resources (Water Science; Technology Board, 1993). Nesse encontro foram abordados os seguintes tópicos: justiça e equidade entre gerações; paisagens, bens de consumo e ecossistemas; as relações entre política e ciências para os rios americanos; ciência hidrológica: mantendo-se em paz com novos valores e percepções, mudando os padrões das tomadas de decisões em recursos hídricos; mudando os conceitos de gestão de sistemas.

Olhar para as paisagens como bem de consumo e ecossistemas, e buscar esse equilíbrio, aponta para uma atitude ambiental responsável. Por sua vez, a mudança de padrões das tomadas de decisões em recursos hídricos está em curso, principalmente no campo teórico, em vários países do mundo. A aproximação entre o modelo teórico e o posto em prática por dirigentes mede o nível de avanço do país ou Estado.

Comparado com o encontro de 1974, os pontos de discussão de 1992 mostram a grande influência da visão ecológica, iniciada na década de 1980, nas abordagens da busca de conhecimento.

\section{As tomadas de decisões: relações entre ciências, técnica, prática social e política}

Mais importante do que decidir como fazer a engenharia da obra é decidir, politicamente, para que desejamos fazer. Essa afirmativa é particularmente verdadeira nas decisões envolvendo a construção de estruturas de recursos hídricos e também das alocações das disponibilidades de águas. Assim, é importante uma análise dos processos de tomada de decisão. J. Habermas (1968, p.109) define três modelos usados na tomada de decisões: o decisionista, o tecnocrático e o pragmático.

No modelo decisionista, há subordinação dos especialistas àqueles que decidem politicamente. Os políticos formulam as opções fundamentais das ações a serem executadas; enquanto os técnicos especialistas são os que fornecem os elementos racionais que validam a execução das ações.

No modelo tecnocrático, o técnico passa a definir as ações. Os problemas são tratados como questões meramente técnicas, ou como equações que devem ser solucionadas pelos especialistas. Ao político cabe o papel de viabilizar, no contexto sociopolítico vigente, as ações preconizadas pela inteligência científica.

Por sua vez, o modelo pragmático envolve um diálogo entre os especialistas e os políticos. Dessa forma, o desenvolvimento de técnicas deve ser encaixado em um "projeto político", o qual deve levar em conta as possibilidades técnicas.

Nos dias atuais, há um novo modelo em construção, trata-se do denomi- 
nado modelo participativo. Em gestão de águas, o modelo consiste em aplicar na prática o princípio da subsidiariedade e da descentralização que estão inseridos na Lei Brasileira de Águas. Em uma visão mais ampla, a gestão participativa está associada ao conceito de democracia participativa como alternativa à democracia representativa.

A tomada de decisões no modelo pragmático deve partir da base de conhecimentos técnicos e científicos acumulados ao longo dos tempos. A Figura 1 apresenta um esquema teórico para descrever um processo de decisões pragmáticas. O esquema busca mostrar uma pirâmide Ideal para a tomada de decisão política. O esquema é válido para os diversos campos do conhecimento, mas neste artigo é analisado para as decisões e ações ligadas à gestão das águas. Descreve-se o processo para moldar, conceitualmente, as decisões em alocação negociada de águas praticada no Ceará, desde a década de 1990.

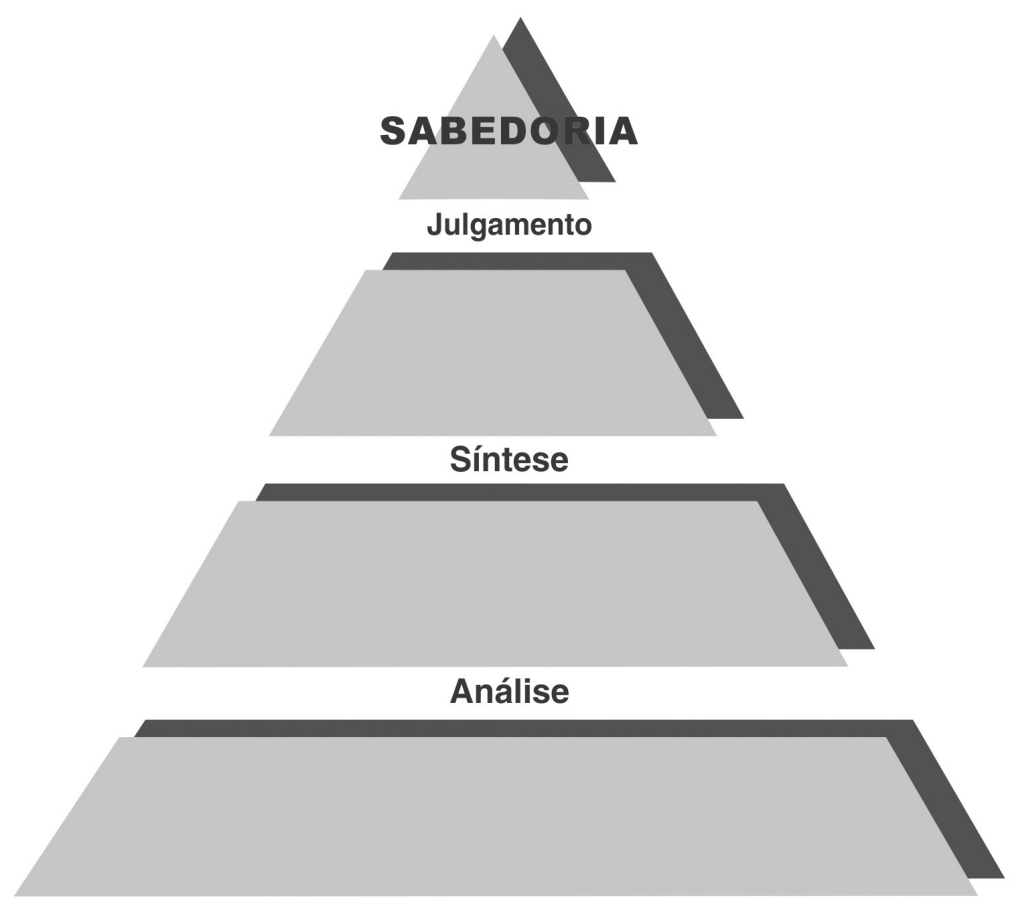

Figura 1 - Pirâmide ideal da decisão pragmática.

\section{Os dados existentes para a gestão de estoques de água}

A primeira etapa do processo de decisão pragmática consiste em coletar os dados relativos ao assunto sobre o qual se pretende tomar as decisões. Assim, para decidir sobre a alocação dos estoques de água, os dados necessários são: níveis históricos de águas nos rios, valores das precipitações pluviais, atividades socioeconômicas relacionadas ao uso das águas, dados morfométricos dos reservatórios, dados climáticos como intensidade de evaporação, e muitos outros. 
Nessa etapa, passa-se a dispor de uma grande quantidade de dados os quais, sem sofrer tratamento analítico, nada informam aos decisores. Por exemplo, com os avanços da internet, técnicos, pesquisadores e a sociedade em geral têm acesso a muitas bases de dados. A Agência Nacional de Águas (ANA) disponibiliza uma extensa base com informações de níveis de águas nos rios, vazões escoadas, precipitações pluviais, níveis de água dos reservatórios.

\section{$A$ análise: dos dados existentes às informações}

A segunda etapa do processo decisório consiste na análise desses dados. Trata-se ainda de uma etapa predominantemente técnica. Os níveis de água nos rios transformam-se em vazões; as leituras dos pluviômetros transformam-se em chuvas nas cidades e bacias hidrográficas, enquanto as atividades sociais e econômicas se transformam em demandas por água. Os dados, coletados na primeira etapa, que não passavam de números e símbolos, passam a quantificar fenômenos naturais e sociais.

$\mathrm{Na}$ seleção dos dados a analisar, o técnico já deve ter conhecimento do problema a resolver. Para isso, ele deve ter a visão política conjunta do ambiente, da sociedade e do problema específico. Da sociedade, deve ter ideia dos anseios e necessidades; do ambiente, deve buscar conhecer as limitações dos recursos naturais, no caso as disponibilidades de águas e os riscos de desabastecimento para certos cenários de uso das águas.

O técnico, ao aplicar os melhores métodos e modelos hidrológicos, desenvolvidos ao longo das gerações, cria cenários possíveis de chuvas e vazões. Há, geralmente, um grande número de informações que fogem ao alcance do leigo. Para uma boa decisão, a síntese é necessária.

\section{A sintese: das informações ao saber}

$\mathrm{Na}$ terceira etapa, faz-se uma síntese das informações. A necessidade da síntese é absolutamente clara hoje em dia quando já se reconhece que informação em excesso pode representar uma forma de ignorância. A gestão dos conhecimentos e das informações constitui-se em um grande tema de pesquisa e de publicações científicas.

Na pirâmide da sabedoria, cabe bem a frase de Cora Coralina (2014): “o saber aprendemos com os mestres e com os livros, a sabedoria se aprende com vida e com os humildes". Assim, ao especialista em Hidrologia cabe o papel dos mestres. Nessa etapa, o especialista deve ter a sensibilidade de aplicar os conhecimentos científicos para propiciar aos decisores uma melhor avaliação das consequências de suas decisões.

O especialista passa a conhecer os regimes hidrológicos dos rios, a partir do conjunto de informações gerados na etapa anterior. Os rios passam a ter vazões médias, regimes de escoamento, perene ou intermitente, variabilidade dos deflúvios anuais e mensais, regime de vazões mínimas etc. Essas grandezas podem ainda ser sintetizadas em disponibilidades hídricas, em riscos de ocorrência 
de cheias e secas etc. As atividades econômicas passam a ter uma determinada demanda por água, passam a querer a água com uma determinada qualidade etc. A reunião dessas grandezas, disponibilidades e demandas pode ser sintetizada em um balanço hídrico.

Finalmente, na quarta etapa, eminentemente política, o conhecimento é aplicado para a sociedade e com a sociedade. Nessa etapa, a técnica desempenha seu real verdadeiro papel, que é de subsidiar a decisão política. Aos conhecimentos acumulados é adicionada a capacidade de julgamento dos decisores. Os bons julgadores, como os bons políticos, inserem a moral, a ética e a experiência para decidirem as ações a serem executadas para enfrentamentos das crises de eventos extremos de águas. Se assim for feito, chega-se a uma sábia decisão.

\section{A expansão do arcabouço institucional para lidar com eventos extremos}

Os eventos extremos em gestão de águas referem-se às secas e às enchentes. Se, por um lado, os impactos das secas no Nordeste foram bastante reduzidos, em decorrência das políticas públicas praticadas desde o início do século $\mathrm{XX}$, por outro, as enchentes têm provocado cada vez mais danos.

A secas hidrológica que atingiu a cidade de São Paulo em 2014 mostra que há novos problemas que requerem mais estudos e novas estratégias para solucioná-los. Os níveis dos estoques de água no sistema Cantareira atingiram os seus valores mais baixos na história no mês de maio de 2014. O problema torna-se mais grave por acontecer quando a demanda, em razão de contínuo crescimento da cidade e das populações, está em seu máximo até os dias atuais. Esse é um alerta que implica que a demanda não pode crescer no atual cenário de oferta e de gerenciamento.

Os debates na mídia e nas comunidades técnicas mostram que há muito a ser feito para que no futuro não ocorram problemas semelhantes, ou mais graves. Nesta seção abordam-se os desafios conceituais para a construção de um novo arcabouço conceitual para lidar com os problemas do futuro.

\section{Tecnologias para o gevenciamento de secas}

O problema das secas tem diversas conotações na literatura técnica. Em essência, a seca é um problema de insuficiência de água, no padrão de qualidade desejável, para atendimento a uma demanda já estabelecida.

As secas ainda se constituem em um grave e crônico problema para a sociedade brasileira. Embora muitos estudos já hajam sido desenvolvidos, há ainda necessidade de formação de conhecimentos sobre o tema.

Uma das carências na questão das secas diz respeito à falta de uma instituição de referência. Na primeira metade do século, o Departamento Nacional de Obras Contra as Secas (DNOCS) desempenhava o papel de formador de conhecimento e de referência Nacional sobre as secas no Nordeste. Após os anos 1960, a Superintendência de Desenvolvimento do Nordeste (Sudene) passou a 
desempenhar esse papel. Todavia, essas instituições têm deixado de lado o exercício desse papel.

No momento atual, pesquisas e estudos são desenvolvidos em diversas universidades e centros de pesquisa. Porém, não há uma real integração entre essas pesquisas e a prática das políticas públicas. Alguns trabalhos científicos já mostram que a política da pequena açudagem, praticada desde a criação do DNOCS já está saturada e pode, em muitos casos, resultar em agravamento dos problemas de escassez de água em vez de solução (Campos, 2015).

Em essência, há uma nova realidade ambiental e institucional, no âmbito da qual muitos conhecimentos precisam ser gerados. Podem ser citados: a inserção do gerenciamento de secas dentro da nova visão de gestão de águas; avaliação dos impactos das políticas públicas de águas no Nordeste nas disponibilidades e qualidade de águas; formação de um quadro conceitual sobre secas.

As secas são fenômenos naturais e inevitáveis. A abordagem de combate às secas tem dois pontos centrais: a antecipação, com previsão, e a preparação para quando a seca se instalar (Drought Preparadness).

Nos Estados Unidos, a NOAA (National Oceanic and Athmosphere Administration) desempenha a função de previsão de secas e coloca as informações disponíveis para a sociedade através do Centro de Informação de Secas (Drought Information Center). As informações e conhecimentos produzidos ficam disponíveis para a sociedade na internet.

Há, também, o National Drought Mitigation Center (NDMC), instituto com sede na Universidade de Nebraska que cria e aplica o conhecimento no planejamento de gerenciamento de secas. Esse instituto funciona como uma referência nacional (Estados Unidos) e internacional no assunto. O instituto oferece uma página na internet com conceitos e muitos conhecimentos ligados ao gerenciamento de secas. Certamente há muitas outras instituições que tratam do assunto. Porém, foram as duas selecionadas para mostrar uma sistemática de lidar com o problema das secas nos Estados Unidos.

No Brasil, o Instituto Nacional de Pesquisas Espaciais (Inpe) funciona como um equivalente ao NOAA. As previsões climáticas relativas às secas no Nordeste são feitas pelo Inpe. As informações são divulgadas e podem ser utilizadas pelos governos estaduais e federal, para estabelecerem ações e políticas de enfrentamento. Contudo, no Brasil não há um equivalente do NDMC, que poderia desempenhar o papel de traduzir, como apoio de conhecimentos científicos, as previsões climáticas, para a formulação de ações políticas.

\section{O gevenciamento de riscos de enchentes}

Extensas superfícies de grandes metrópoles brasileiras estão sofrendo frequentemente severas inundações que paralisam o andamento normal das atividades das cidades e, algumas vezes, têm resultado em perdas de vidas humanas. Cidades como São Paulo, Rio de Janeiro, Recife e Blumenau têm convivido com esses problemas. 
Como no caso do atendimento das demandas em águas, as soluções procuradas são, principalmente, de ordem estrutural. Constroem-se grandes barragens que passam a ser operadas para controlar as cheias; constroem-se canais para acomodar as cheias dos rios; constroem-se piscinões para atuarem no amortecimento de cheias etc. Mais recentemente, as soluções não estruturais são buscadas, porém, muitas vezes, já não conseguem solucionar problemas graves já instalados.

Há ainda muito a estudar e a conhecer nesse tema. A produção de conhecimento pode ajudar a responder questões como: qual a tendência atual das perdas econômicas decorrentes das inundações? As perdas tendem a aumentar? Tendem a estabilizar? Tendem a diminuir? Como as cidades brasileiras que ainda não estão sofrendo o problema com gravidade estão agindo para evitá-lo no futuro?

A regulamentação da ocupação das atuais e futuras planícies de inundações, baseada nos exemplos vivenciados e em suas análises teóricas, há de permitir que as cidades em desenvolvimento possam planejar e usar melhor suas planícies de inundações.

Os Estados Unidos têm lidado com o problema das enchentes urbanas, porém sem resolvê-lo, usando a tecnologia de satélites e sistemas de alarme para a população. A previsão de episódios de enchentes e outras catástrofes climáticas relativas aos estados de curto tempo da atmosfera evoluiu substancialmente com o advento dos satélites meteorológicos. Nos Estados Unidos, a NOAA dispõe de um sistema de observação que está continuamente analisando a atmosfera e aplicando modelos matemáticos de previsão.

No Brasil o sistema de prevenção e alerta de desastres naturais está nos primeiros anos de funcionamento. Há o Centro Nacional de Monitoramento e Alertas de Desastres Naturais (Cemaden) que tem como missão desenvolver, testar e implementar um sistema de previsão de ocorrência de desastres naturais em áreas susceptíveis de todo o país. Em termos de pesquisas, o Cemaden dá ênfase em previsão, preparação, prevenção e mitigação do impacto de eventos extremos em bacias hidrográficas urbanas e rurais com reduzido tempo de resposta. Com os conhecimentos, o Cemaden espera reduzir perdas em vidas humanas e materiais em decorrência dos eventos críticos.

Há também o Centro Nacional de Gerenciamento de Riscos e Desastres (Cenad) criado em 17 de fevereiro de 2005. O Cenad é vinculado ao Ministério da Integração, sob a coordenação da Secretaria Nacional de Proteção e Defesa Civil. Cabem ao Cenad as ações de planejamento e mobilizações para atuação em situações de riscos e de desastres. Para uma instituição com nove anos de existência, ainda em fase de crescimento, há, certamente, necessidade de formação de muitos conhecimentos científicos. Os conhecimentos gerados pela Cenad situam-se nas ciências empíricas e nas ciências sociais à medida que lidam com mobilizações de populações. 


\section{Reflexões finais}

Um dos primeiros registros sobre a necessidade de gerar conhecimentos e técnicas para resolver novos problemas de escassez de água, decorrentes do modelo de desenvolvimento vigente, é devido a Hall (1972). O autor afirmou que não se podiam resolver os problemas do futuro com os conhecimentos e as tecnologias de então; mesmo considerando que as tecnologias fossem apropriadas para os problemas correntes. Havia, nas palavras de Hall, uma antecipação do que viria nos anos 1980 com os conceitos de desenvolvimento sustentável.

Nos anos 1970, os problemas de recursos hídricos eram considerados problemas de engenharia que podiam ser resolvidos com obras hidráulicas. A hidrologia gerava conhecimentos para aplicação, principalmente, na engenharia hidráulica. A percepção de Hall (1972) era de que os problemas estavam se tornando mais complexos e que a capacidade da engenharia de solucioná-los estava se exaurindo.

A partir da década de 1980, a sociedade direcionou muitos esforços para a geração de conhecimentos sobre gestão de águas, juntando ciências empíricas, como hidrologia e meteorologia, e as ciências sociais, como economia e administração. Um novo arcabouço conceitual para resolver os problemas de água foi criado.

Por volta do ano 2000, o desenvolvimento industrial, a intensa utilização de recursos naturais, os poluentes lançados por chaminés na atmosfera continuavam criando novos problemas. Falkenmark (2000) percebeu a dificuldade que a sociedade enfrentava com problemas cada vez mais complexos e alertou que o arcabouço conceitual herdado do passado se mostrava insuficiente para solucionar os crescentes problemas relacionados aos usos de águas no futuro.

As reflexões de Hall (1972) e Falkenmark (2000) indicam que os estudos e as pesquisas em recursos hídricos são indispensáveis para se resolver os problemas atuais. Também, as dinâmicas ambientais do mundo contemporâneo exigem uma constante atualização nos métodos de pesquisa. As ciências empíricas, as ciências sociais e as práticas políticas devem ser integradas nos moldes da pirâmide ideal da decisão política.

No Brasil, há muitos problemas graves para os quais ainda não se dispõem conhecimentos e tecnologias. As enchentes urbanas estão cada vez mais devastadoras de bens materiais e de vidas humanas. O país está envidando grandes esforços no sentido e criar e aperfeiçoar sistemas de alertas para minimizar os impactos das enchentes.

Em síntese, em termos de gestão de recursos hídricos, há no Brasil ainda um acentuado déficit de conhecimentos e tecnologias em gestão de águas. Dessa forma, há um passivo a ser pago e investimentos a serem feitos para o bem-estar das futuras gerações; tudo no âmbito do conceito de justiça entre gerações.

Um novo mundo está sendo desenhado em termos da gestão de águas. 
Novos conhecimentos são requeridos. Novas visões e atitudes de pesquisadores são demandadas para a busca de soluções para esse novo mundo.

A Hidrologia constitui-se na ciência fundamental para propiciar uma eficiente gestão de águas. A importância das águas para o sistema Terra tem intensas implicações para a infraestrutura educacional e de pesquisa das ciências hidrológicas.

A nova visão da pesquisa científica no mundo deve estar associada aos aspectos relacionados com as ciências sociais e as ações políticas. Se houve, e continua havendo, mudanças substanciais na maneira de administrar e usar as águas, certamente deve-se também mudar a maneira de estudar e ver os problemas. A inter e a multidisciplinaridade devem ser preocupação central da pesquisa.

Para os epistemólogos é lamentável o fato de cientistas não estudarem o processo crítico e a formação dos conceitos e teorias que aplicam. Assim aprendidos eles transformam-se em dogmas e inibem o avanço do conhecimento científico. Para o tema gestão de águas, há muita carência para esse tipo de estudo. A avaliação histórica da formulação e evolução do nosso sistema de gerenciamento dos recursos hídricos deve gerar conhecimentos que podem permitir o aperfeiçoamento do atual ser aplicados no aperfeiçoamento do sistema.

\section{Referências}

ABES. Associação Brasileira de Engenharia Sanitária e Ambiental. Perdas em sistemas de água: diagnóstico, potencial de ganhos com sua redução, proposta de medidas para efetivo combate. São Paulo: Abes, 2013.

CAMPOS, J. N. B. Secas e políticas públicas no semiárido: ideias, períodos e pensadores. Estudos Avançados, São Paulo, v.28, n.82, p.65-88, 2014.

Paradigms and public policies on drought in Northeast Brazil: a historical perspective. Environmental Management, v.55, p.2052-63, 2015.

CAMPOS, J. N. B.; STUDART, T. M. C. An historical perspective on the administration of water in Brazil. Water International, v.25, p.148-56, 2000.

CORALINA, C. Frases. Disponível em: <http://frases.globo.com/cora-coralina/5523>. Acesso em: 18 jul. 2014.

FALKENMARK, M. Competing freshwater for ecological services in the river basin perspective: an expanded conceptual framework. Water International, v.25, n.2, p.1727,2000 .

GONÇALVES, V. B. O princípio da precaução e a gestão dos riscos ambientais: contribuições e limitações dos modelos econômicos. Ambiente es Sociedade, v.XVI, n.4, p.121-40, 2013.

GRANZIERA, M. M. L. A cobrança pelo uso da água. Revista CEJ, v.4, n.12, p.71-4, 2000.

HABERMAS, J. Técnica e ciência como "ideologia”. Trad. Artur Morão. Lisboa: Edições $70,1968$. 
HALL, W. A. Research in support of planning and management of water and related land resources. In: ORGANIZATION FOR ECONOMIC COOPERATION AND DEVELOPMENT. Water management: basic issues. Paris: OECD, 1972 p. 263-70.

INCE, S. Some early attempts at theory formation in Fluid Mechanics. In: LANDA, E. R.; INCE, S. History of Geophysics. Washington, D.C.: American Geophysical Union, 1987. v.3 "History of Hydrology", p.35-38.

MAGEE, B. História da filosofia. 2.ed. São Paulo: Edições Loyola, 2000.

MOTTA, R. S. Utilização de critérios econômicos para a valorização da água no Brasil. Rio de Janeiro: Secretaria de Estado de Meio Ambiente, 1998.

NATIONAL ACADEMY OF SCIENCES. More water for arid lands. Washington, D.C: NAS, 1974.

RIBEIRO, M. M. R.; LANNA, A. E.; PEREIRA, J. S. Elasticidade-preço da demanda e a cobrança pelo uso da água. In: XIII SIMPÓSIO BRASILEIRO DE RECURSOS HÍDRICOS. Anais... Belo Horizonte: ABRH, 1999.

UNITED NATIONS. The future we want. Outcome of Rio + 20, United Nations Conference on Sustainable Development. Rio de Janeiro: United Nations, 2012.

UNITED NATIONS ENVIRONMENT PROGRAMME - UNEP. Towards a green economy: pathways to sustainable development and poverty eradication. Geneva: UNEP, 2011.

VIEIRA, R. S. RIO+20 - Conferência das Nações Unidas sobre Meio Ambiente e Desenvolvimento: contexto, principais temas e expectativa em relação ao "Direito da Sustentabilidade”. Novos Estudos Jurídicos, v.17, n.1, p.48-69, 2012.

VIESSMAN, W.; WELTY, C. Water management: technology and institutions. New York: Harper \& Row, 1985.

WATER SCIENCE; TECHNOLOGY BOARD. Sustaining our resources. National Academy. Washington D.C: The National Academies Press, 1993.

WCED - World Commission on Environment and Development. Our common future. Oxford: Oxford University Press, 1987.

WHEATON, B. R. The last word on science. Eos, Transactions, America Geophysical Union, v.66, n.47, p.1181-3, 1985.

RESUMO - O artigo apresenta estudo sobre os conhecimentos científicos em gestão de águas e suas aplicações na prática social e política. Desenvolve-se a partir de uma base de conceitos da formação dos conhecimentos em matemáticas, ciências empíricas e ciências sociais. Apresentam-se visões sobre os problemas de escassez na década de 1970 e na década de 1990. As mudanças de visões, decorrentes de mudanças de paradigmas, ficam evidentes. Em seguida, desenvolve-se o caminho para decisões em gestão de águas. O processo de decisão é esquematizado em forma de pirâmide, que tem na base a obtenção de dados para a aplicação das ciências hidrológicas, até o topo onde se toma uma decisão política. Uma aplicação desse modelo teórico é descrita. Desafios para a busca de novos conhecimentos para administrar a dinâmica de uso dos recursos hídricos são apresentados.

PALAVRAS-CHAVE: Formação dos conhecimentos, Gestão de águas, Gestão de secas. 
ABSTRACT - This article presents a study of the scientific knowledge in water management and their applications in social and political practice. The paper develops concepts of the formation of knowledge in mathematics, empirical science, and social sciences. The vision for solving water shortages problems in the 1970s and 1990s presented. Changes in vision, due to paradigm shifts, become evident. Thereafter, the paper develops the knowledge of the ideal pyramid for political decision. The decision process, outlined in the classic pyramid shape, the base starts with data collection to apply in hydrological sciences, towards the top where a political decision concluded. The message of the article is that scientific knowledge generated provides the support for the water management model practiced in Brazil. Challenges in the pursuit of new knowledge to manage the dynamics of the uses of water resource discussed.

KEYWORDS: Water management, Decision making, Building knowledge.

José Nilson B. Campos é professor do Programa de Recursos Hídricos da Universidade Federal do Ceará (UFC) e pesquisador IB do CNPq. Foi presidente da Associação Brasileira de Recursos Hídricos de 2003 a 2005. Coordenador adjunto da Capes em Engenharias I de 2007 a 2010. @ - nilson@ufc.br

Vanessa Ribeiro Campos é professora do Departamento de Engenharia Estrutural e Construção Civil da Universidade Federal do Ceará (UFC). Tem mestrado em Engenharia de Produção pela Universidade Federal de Pernambuco (2004) e doutorado em Engenharia de Produção pela Escola de Engenharia de São Carlos - USP (2011).

@ - nessarc@gmail.com

Recebido em 12.6.2015 e aceito em 8.7.2015.

${ }^{\text {I }}$ Departamento de Engenharia Hidráulica e Ambiental, Universidade Federal do Ceará. Fortaleza/CE, Brasil.

II Departamento de Engenharia Estrutural e Construção Civil, Universidade Federal do Ceará. Fortaleza/CE, Brasil. 